\title{
Using communication research to gather stakeholder preferences to improve groundwater management models: a South Texas case study
}

\author{
Ric Jensen, Venkatesh Uddameri
}

\begin{abstract}
There is a compelling need to ensure that the points of view and preferences of stakeholders are fully considered and incorporated into natural resources management strategies. Stakeholders include a diverse group of individuals in several sectors that have an interest in how natural resources are managed. Typically, stakeholders with an interest in groundwater resources include groups who could be affected by the manner in which the resource is managed (e.g., farmers who need water for irrigation; municipalities and individuals who need drinking water, agencies and organizations that want to maintain in-stream flows to support ecosystems, etc.) Refugio County in South Texas provides an interesting case study since several groups of water users in the region are working with researchers at Texas A\&M University-Kingsville (TAMUK) to develop decision-support models that incorporate stakeholder concerns.

The focus of this paper is to provide a series of arguments and approaches about the ways in which stakeholder issues have recently been incorporated into environmental models, to briefly describe some of the TAMUK efforts to develop groundwater models that incorporate stakeholder inputs, and to present and discuss a method in which communication research can be used to obtain stakeholder preferences input into modeling efforts.
\end{abstract}

\section{Introduction}

The study area consists of Refugio County in South Texas. In this region, groundwater provides several ecosystem services: it supplies water for irrigation and drinking and it supplies flows to streams, rivers, and bays. Since 2000 , stakeholders in the region have been trying to come to terms with the best way to manage groundwater resources. Large municipalities located outside the region have proposed plans to export water supplies from Refugio County to other basins. Within the region, there are concerns about the extent of pumping that can be allowed without creating saltwater intrusion or mining groundwater resources.

Texas water laws enable individual landowners to largely decide the amount of water they wish to pump. In addition, local groundwater management districts in the region regulate well spacing and encourage best management practices to protect aquifer supplies and water quality. In many cases (including the area of this study) groundwater districts are aligned along county boundaries-not the natural geography of the aquifer.

Since 2005, the Texas Legislature divided the state into 16 groundwater management areas (GMAs) and mandated that each of these regions go through a joint planning process to manage aquifer resources. Texas' groundwater joint planning process is designed to be stakeholder-driven and participatory. The intent is that stakeholders will help create groundwater management plans that reflect various water needs and are compatible with groundwater supplies. The groundwater planning process is intended to be compatible with larger-scale regional and state water resources planning processes that were earlier put forth in 1997.

In many regions, the challenge of developing groundwater management strategies is difficult since a delicate balance must be struck between water supply needs for humans and the environment. In these instances, where many competing interests have to be considered simultaneously, groundwater models can help stakeholders and decision makers evaluate the issues and anticipate the outcomes of management actions. The models are most useful if they are based on real-world scenarios, if they are developed with stakeholder input, and if they present information using a format that the public can easily understand and use. 


\section{The importance of communication research to better understand stakeholder relations}

\subsection{Use of qualitative and mixed-method tools to examine communications processes within groups of environmental stakeholders}

Stakeholders can provide valuable inputs about natural resources issues. Once models have been developed, stakeholders can offer insights about the extent to which groundwater models accurately represent local conditions and whether decision makers are likely to use these tools.

Denzin \& Lincoln [4] advocate that naturalistic and qualitative methods (i.e., grounded theory, content analysis, and case studies) should be utilized more fully to better understand how stakeholders prioritize concerns about natural resources. The National Science Foundation (2002) suggests that a "mixed-methods" approach, in which qualitative and quantitative methods are used, can provide the best insights about natural resources management. Hocking, Stacks \& Bacon [5] suggest that the use of qualitative tools in mixedmethods research can provide insights that cannot be obtained through the use of empirical surveys. Mixedmethod approaches draw upon the points of view of participants and use grounded theory to guide future data gathering. McBeth et al. [11] used content analysis to identify messages being communicated by prodevelopment and habitat preservation groups related to Yellowstone Park. The research team developed quantitative statistics to compare the rhetoric of these diverse groups.

Many scholars suggest that fostering communication between stakeholders in focus groups, listening sessions, and open forums can lead to a better understanding of how different constituencies view natural resources issues. Pahl-Wostl [14] describes the use of qualitative methods (i.e., in-depth interviews, discussion panels, etc.) to increase the participation of stakeholders in the watershed planning process. Wagenet \& Pfeffer [20] suggest that environmental policy is best implemented when stakeholders are actively involved in decision making processes. Buysse \& Verbeke [1] identified the relationships between environmental organizations and stakeholder groups in Europe. They found that organizations that want to be perceived as environmental leaders work harder to listen to stakeholder concerns and incorporate their inputs into strategic management and communication efforts.

\subsection{Using input from stakeholders to gain in environmental modeling}

Several recent studies have explored how stakeholder groups can provide feedback about the concepts presented in water resources and environmental models and the data generated by these simulation tools. Clark et al. [2] discuss how efforts by scientists to educate and inform a range of stakeholder groups about groundwater pollution and clean-up efforts at the Rocky Flats Superfund site in Colorado increased mutual understanding, accelerated the amount of time it took to complete technical studies and begin cleanup, and saved taxpayers millions of dollars. Olsson \& Berg [13] discuss how stakeholders provided feedback about water quality modeling in Scandinavia. Results show stakeholders were concerned about whether the data were trustworthy, the extent to which the models accurately represented real-world issues, and the quality of input data. Jonsson [8] stressed that dialog must be fostered between researchers and stakeholders in local watershed councils, and complex technical information has to be presented so stakeholders can understand the practical implications of modeling studies. Uddameri [19] described how environmental decisionmaking models can be customized using multiple criteria to provide stakeholders with a range of technical preferences they can choose from that best reflect their priorities.

Recent watershed planning crises have occurred when efforts were not made to clearly communicate with stakeholders. The United States Government Accounting Office (2005) reported about a breakdown in communication between federal government agencies and stakeholders in the Klamath River basin of Oregon that hindered the development of water management planning efforts. Moore [12] described this crisis and concluded that water management agencies did not make adequate efforts to communicate with stakeholders. Darnell \& Jolley [3] describe how involving stakeholders in water resources decision-making processes is most effective if technical information is communicated in terms the public can understand. 


\section{Research at Texas A\&M University-Kingsville to incorporate stakeholder concerns into groundwater modeling}

Since 2001, researchers in the Environmental Engineering Department at Texas A\&M UniversityKingsville have carried out a series of studies to determine how stakeholder concerns can be incorporated to improve groundwater management models. Uddameri, Kuchanur, \& Balija [18] suggest that local groundwater management is a multi-stakeholder process wherein competing objectives and different sets of values and perceptions have to be reconciled. Uddameri (2006) states that interactive groundwater models intended to effectively communicate with the public can help stakeholders better understand the economic, environmental and ecological implications of proposed aquifer management strategies.

The Texas Water Resources Institute funded a study to investigate the extent to which game theory could be used to determine the technical preferences of stakeholders related to groundwater management in the region, thus providing data to drive management models [10]. In particular, conflicting stakeholder preferences with regards to groundwater use and conservation can be captured using mixed-methods research and combined with groundwater availability models to estimate payoffs (total economic and ecological benefits) under different stakeholder preferences. Economic benefit was measured as the amount of groundwater available for use. Ecological benefits and concerns were incorporated into the model in such a way that the simulations did not include groundwater production that may damage the groundwater resource. These constraints included restricting levels of groundwater pumping to limit saltwater intrusion and mining (excessive drawdowns) and major changes in flow patterns (hydraulic gradients), and to ensure that aquifer withdrawals would not significantly decrease stream flows to streams and estuaries [16]. Mathematical concepts from game-theory were then used to evaluate strategic solutions that are sustainable from economic and environmental standpoints. In a related study, Uddameri \& Honnungar [17] used a "fuzzy" regression methodology to allow stakeholders to identify specific technological preferences. For example, the fuzzy framework allows individuals to select a numerical value that represents conditions they deem to be acceptable (e.g., how many feet of aquifer drawdown should be permitted, etc.) and allows stakeholders to judge the extent to which they accept the model to be suitable for planning and management purposes.

\section{Using communication research to learn about stakeholder preferences related to groundwater modeling at Texas A\&M University-Kingsville}

This research was conducted as a component of comprehensive efforts to incorporate stakeholder preferences in computer models being developed at Texas A\&M University-Kingsville. The overall goal was to determine if focus groups, content analysis, and related methods could be used to determine the technical preferences of stakeholders about groundwater issues in the region.

The study consisted of the following steps:

- Developing information that can be used in the focus groups.

- Conducting focus groups to gain initial insights.

- Carrying out discussions with the actual stakeholders.

\subsection{Developing information that can be used in the focus groups}

In March 2005, the Technical Stakeholder Forum met in the town of Refugio. This forum was led by a moderator trained in watershed issues facing the region. Major topics that were discussed included a proposal by a city to export water from the region (the Lower Guadalupe Water Supply Project) and its potential impact on groundwater supplies in Refugio County, groundwater availability models developed by the Texas Water Development Board, and the adverse effects of groundwater pumping on water availability, water quality, and saltwater intrusion. Information from this meeting was gleaned and used to prepare for focus groups to test the extent to which this method could be used to obtain stakeholder preferences. 


\begin{tabular}{|l|}
\hline Should the model allow for maximum groundwater pumping? \\
\hline Should the model allow for saltwater intrusion to occur? \\
\hline Should the model allow for groundwater pumping to decrease freshwater inflows? \\
\hline Should landowners be allowed to trade groundwater rights? \\
\hline How should the drought of record influence groundwater management? \\
\hline How much groundwater drawdown is acceptable? \\
\hline Should groundwater monitoring wells be required? \\
\hline
\end{tabular}

Table 1. Questions Asked during the Focus Groups.

\subsection{The focus group}

In May 2005, researchers met with faculty and graduate students in the Texas A\&M UniversityKingsville College of Engineering to test the focus group protocol developed for this project. The primary purpose of conducting a focus group was to develop and refine the procedures to be used to in real-world settings. In addition, time and logistic constraints and the controversial nature of the topic precluded carrying out such an exercise with a real-world audience. Participants consisted of six graduate students at Texas A\&M University-Kingsville. The session lasted about 2 hours. In the focus group, a comprehensive overview of TAMUK groundwater modeling efforts was presented. A moderator asked participants to provide input about their technical preferences related to specific groundwater management issues. At points in the session, participants were asked to record their technical preferences on a written survey form. The survey form included questions using a Likert scale (where a response of " 1 " means the issue is not thought be important, while a response of " 5 " suggests the issue is very important). Methodology for the use of Likert scales is described by Jamieson [6]. In addition, other questions asked participations to provide a numeric response (e.g., the volume of groundwater users should be allowed to pump per year, etc.). An observer recorded comments made by participants as well as notes about communications dynamics within the group. After the meetings, transcripts were analyzed using content analysis to identify important themes that were discussed using qualitative and naturalistic methods [4].

Questions asked of focus group participants are shown in table 1. The major goal of the focus group was to identify the diverse interests of stakeholders with regards to economic and environmental issued. Stakeholders seldom know how to verbalize their preferences with regards to the above mentioned issues. The role of the facilitator was to introduce the question, promote participation and seek clarification with regards to comments made by the stakeholder and facilitate a healthy discussion. Another important task was to ensure that the preferences of the stakeholders were captured in such a way they could provide inputs to models.

\subsection{The August 2005 technical stakeholders group workshop}

In August 2005, the Refugio County Groundwater Conservation District held a meeting of the Technical Stakeholder Group in Refugio to develop criteria for new groundwater management rules. Stakeholder comments were recorded and analyzed using qualitative methods and themes from the data were identified.

Some of the topics that were presented included:

- Scientific approaches used to develop groundwater production rules,

- Development of a conservative modeling approach to manage groundwater that would not deplete the aquifer or harm adjoining users,

- Data collection needs,

- The use of modeling tools to simulate random conditions,

- The use of monitoring wells to detect changes in groundwater quality,

- The extent to which modeling results match real-world conditions.

Participants discussed how the Texas A\&M-University-Kingsville modeling studies could be applied to develop groundwater management rules about baseline and high-volume pumping rates and monitoring strategies. 


\begin{tabular}{|l|l|}
\hline A uniform pumping rate should be assigned to all users & 5.0 \\
\hline Concerns of adjacent counties should be considered & 4.5 \\
\hline The model should simulate saltwater intrusion & 3.8 \\
\hline $\begin{array}{l}\text { The model should simulate conditions where all county residents } \\
\text { should have equal access to groundwater }\end{array}$ & 3.3 \\
\hline The model should simulate groundwater marketing scenarios & 3.0 \\
\hline The model should simulate effects of pumping on stream flows & 2.8 \\
\hline The model should simulate effects of pumping on flows in bays & 2.6 \\
\hline
\end{tabular}

Table 2. Technical Preferences of Focus Group Participants about Groundwater Issues (results are based on a Likert scale where $1=$ indicates not important and $5=$ very important).

\subsection{Results}

The March 2005 Technical Stakeholders Workshop provided insights about the types of questions that should be asked in the focus groups. Some stakeholders expressed concerns about the potential effects of groundwater pumping on water quality, and the need to develop groundwater management models that can incorporate the technical preferences of stakeholders to simulate complex hydrologic processes in the region. After this meeting, user-friendly publications were developed to explain the project to the public and to recruit stakeholders to participate in upcoming focus groups.

Results from the focus group are presented in table 2. Results show that these stakeholders strongly preferred that a uniform rate of pumping be assigned to all water users in the region (an average of score of 5 on the Likert scale) and that the concerns of adjacent counties be incorporated into modeling scenarios (4.5). To a lesser extent, focus group participants desired that the model simulate the effects of groundwater pumping on saltwater movement (3.8) and that the model should reflect how groundwater pumping affects streamflows (3.0). Stakeholders believed the allowable level of groundwater pumping should to be tied to the drought of record; felt that some level of aquifer drawdown resulting from groundwater pumping is acceptable, and wanted the model to be able to simulate conditions in which groundwater rights are being traded. The small sample size (6 participants) made it difficult to carryout a detailed statistical evaluation of the data. Qualitative analysis of the results indicated that there was a greater agreement with regards to the need for equitable distribution of groundwater to all users within the district as well as ensuring that groundwater pumping not limit the availability in neighboring areas. A lesser agreement was noted with regards to the environmental effects of groundwater pumping particularly with respect to salt-water intrusion and exchange of groundwater with surface water bodies.

At the August 2005 Technical Stakeholders Group workshop, major topics of discussion focused on the merits of proposed groundwater management rules, new developments in groundwater modeling, and the effects of aquifer pumping on water quality and water supplies. Results are shown in table 3. The technical stakeholder group were particularly focused on rules and regulations of groundwater. There was also a considerable interest in understanding the role of groundwater models and their utility in policy making. Environmental considerations such as groundwater quality attracted limited attention. Only a few workgroup members expressed a desire towards discussing ways to allocate water among different user groups with the majority favoring policies that foster equal distribution to all persons within the district. These results are consistent with the results obtained from the focus group and indicate the usefulness of carrying out such exercises.

\section{Summary and conclusion}

This project demonstrates that communications research can be very useful in developing groundwater models that reflect stakeholder preferences. Content analysis of stakeholder groups provided a basis to develop questions that could be asked in focus groups and surveys. Focus groups were proven to be a method through which the technical preferences of stakeholders could be obtained. Those technical preferences can be incorporated into groundwater management models. 


\begin{tabular}{|l|l|}
\hline Topic & Number of comments \\
\hline Local groundwater management rules & 57 \\
\hline TAMUK modeling studies & 33 \\
\hline Specific local conditions & 21 \\
\hline Effects of pumping on water quality and water supplies & 19 \\
\hline The need for groundwater monitoring & 8 \\
\hline Groundwater allocation strategies & 7 \\
\hline
\end{tabular}

Table 3. Topics Most-Often Addressed in Stakeholder Forums.

In broad terms, communication research methods can be used to develop and carry out modeling runs that most closely reflect the concerns and priorities of stakeholders. By presenting the models to stakeholders, researchers can get feedback about the extent to which these tools are thought to accurately reflect real-world conditions. In addition, incorporating the preferences of stakeholders makes the process of developing model runs more efficient. If technical preferences can be obtained from stakeholders, researchers can reduce the number of model runs that need to be carried out to meet the most important concerns.

The research team at Texas A\&M University-Kingsville continues to work to gather data on the technical preferences of stakeholders that can be incorporated into sophisticated computer models. The ultimate goal is to create groundwater models that fully take advantage of the local knowledge of stakeholders and incorporate their concerns into studies of how groundwater supplies can best be managed.

There will likely be many future opportunities to study stakeholder issues related to water resources and the environment in South Texas. In October 2007, stakeholders expressed concerns about new efforts to mine uranium that may harm water quality in the region. More plans to export groundwater out of the region are likely to be developed as competition for limited water resources intensifies. When future water crises occur, it will become especially important to have groundwater models in place that can analyze these complex, interrelated, water resources issues.

In recent years, the use of computer models for understanding the flow of water and for predicting water availability under different natural and anthropogenic stresses is becoming more commonplace. In addition, there has been considerable emphasis on managing water resources using stakeholder-driven participatory frameworks. It is imperative that stakeholders understand the workings of mathematical models and be able to specify their preferences with regards to various water management scenarios. This case study emphasizes that active collaborations should be developed between communication specialists and water resource engineers to properly capture stakeholder preferences and foster a risk-informed dialogue necessary for sustainable water resources management.

\section{Limitations}

This study has several limitations. More opportunities should have been developed to interact with local stakeholders. Because groundwater management was a contentious political issue in the region, some stakeholders were reluctant to discuss these controversies. More focus groups should have been carried out with different target audiences, ideally local residents with knowledge of water resources in the region to obtain a better delineation of stakeholder preferences. Nonetheless, the study demonstrates that even limited interactions with stakeholders can generate significant insights and is preferable to carrying out insular groundwater modeling studies with no feedback or interactions.

\section{Acknowledgments}

"This material is based on works supported by the Center for Research Excellence in Science \& Technology-Research on Environmental Sustainability of Semi-Arid Coastal Areas (CREST-RESSACA) at Texas A\&M University-Kingsville through a cooperative agreement (HRD \#006259) with the National Science Foundation (NSF). Any opinions, findings, conclusions or recommendations expressed in this material do not necessarily reflect the views of the NSF." The anonymous referees are thanked for their critical review and constructive comments that greatly improved the quality of this manuscript. 


\section{Notes and references}

[1] K. Buysse and A. Verbeke (2003), Proactive Environmental Strategies: A Stakeholder Management Perspective, Strategic Management Journal 24, 453-470.

[2] D. Clark et al. (2007), Rocky Flats Closure: The Role of Models in Facilitating Communication with Stakeholder Groups, Journal of Alloys and Compounds 444, 11-18.

[3] N. Darnell and G. Jolley (2004), Involving the Public: When Are Surveys and Stakeholder Interviews Not Effective?, Review of Policy Research 21, 581-593.

[4] N. Denzin and Y. Lincoln (1998), Collecting and Interpreting Qualitative Materials, Sage Publishing, Thousand Oaks, California.

[5] J. Hocking, D. Stacks and S. McDermott (2005), Communication Research, Allyn \& Bacon Publishing, Boston, Massachusetts.

[6] S. Jamieson (2004), Likert Scales: How to (Ab)use Them, Medical Education 38, 1217-1218.

[7] R. Jensen (2005), Use of Qualitative Methods to Obtain Stakeholder Preferences to Support Groundwater Modeling in South Texas, Technical report submitted to the Center for Environmental Research in Science and Technology, August 2005.

[8] A. Jonsson (2005), Public Participation in Water Resources Management: Stakeholder Voices on Degree, Scale, Potential, and Methods in Future Water Management, Ambio 34, 495-500.

[9] Klamath River Basin: Reclamation Met its Water Bank Obligations, but Information Provided to Water Bank Stakeholders Could be Improved. 2005. United States Government Accounting Office.

[10] M. Kuchanar (2006), A Decision Support System to Develop Sustainable Groundwater Management Policies for a Multi-County Single Aquifer System, Proposal funded by the Texas Water Resources Institute. On the web at http://twri.tamu.edu.

[11] M. McBeth, E. Shanahan and M. Jones (2005), The Science of Storytelling: Measuring Policy in Greater Yellowstone. Society and Natural Resources 18, 413-429.

[12] M. Moore (2006), I, Me, Mine: On the Rhetoric of Water Wars in the Pacific Northwest, The Environmental Communication Yearbook, 1-19.

[13] J. Olsson and K. Berg (2005), Local Stakeholders' Acceptance of Model-Generated Data Used as a Communication Tool in Water Management: The Ronnea Study, Ambio 34, 507-512.

[14] P. Pahl-Wostl (2002), Participative and Stakeholder-Based Policy Design, Evaluation, and Modeling Processes, Integrated Assessment 3, 3-14.

[15] The 2002 User-Friendly Handbook for Project Evaluation (2002), National Science Foundation.

[16] V. Uddameri and M. Kuchanur (2007), Simulation-Optimization Approach to Assess Groundwater Availability In Refugio County, Texas, Environmental Geology 51, 921-929.

[17] V. Uddameri and V. Honnungar (2007), Interpreting Sustainable Yield of an Aquifer Using A Fuzzy Framework, Environmental Geology 51, 911-919.

[18] V. Uddameri, M. Kuchanur and N. Balija (2006), Optimization Approaches for Groundwater Management, Chapter 11 in Aquifers of the Gulf Coast of Texas, Texas Water Development Board Report 365, 205-216.

[19] V. Uddameri (2003), Using the Analytic Hierarchy Process for Selecting an Appropriate Fate and Transport Model for Risk-Based Decision Making at Hazardous Waste Sites, Hazardous, Toxic, and Radioactive Waste Management 7, 139-146.

[20] L. Wagenet and M. Pfeffer (2004), Stakeholder Participation in Watershed Management, Environment and Society 5, 1-13. 


\section{Authors}

Ric Jensen is an Assistant Professor in the Department of Contemporary Media and Journalism at the University of South Dakota. His teaching and research interests include using naturalistic research to study issues related to the environment, how environmental issues are communicated, and increasing public understanding of science. E-mail: ric.jensen@usd.edu.

Venkatesh Uddameri is an Associate Professor in the Department of Environmental Engineering at Texas A\&M University-Kingsville. He has led several studies to develop groundwater management models that incorporate the technical preferences of stakeholders as inputs. E-mail: vuddameri@tamuk.edu.

HOW TO CITE: R. Jensen and V. Uddameri, Using communication research to gather stakeholder preferences to improve groundwater management models: a South Texas case study, Jcom 08(01) (2009) A02. 